\title{
Frequency of Complications after Electroconvulsive Treatment in Patients with Schizophrenia
}

\author{
MUAMMAD UMAR MARRI ${ }^{1}$, ZAINULLAH KHAN ${ }^{2}$, ALI AHSAN MUFTI ${ }^{3}$, EJAZ GUL ${ }^{4}$, ASIF KAMAL $^{5}$ \\ ${ }_{1,2}$ Assistant Professors, Department of Psychiatry, Balochistan Institute of Psychiatry \& Behavioural Sciences, Quetta \\ ${ }^{3}$ Assistant Professor of Psychiatry, Jinnah Medical College Peshawar \\ ${ }^{4}$ Professor of Psychiatry, Bacha Khan Medical College Mardan \\ ${ }^{5}$ Professor of Psychiatry, Gajju Khan Medical College Swabi \\ Correspondence to: Dr. Zainullah Khan, E-mail: zainbazai78@gmail.com Cell 0321-8105050
}

\begin{abstract}
Objective: To determine the frequency of complications after electroconvulsive treatment in patients with schizophrenia.

Study Design: Retrospective study

Place and Duration of Study: Department of Psychiatry, Balochistan Institute of Psychiatry \& Behavioural Sciences, Quetta $1^{\text {st }}$ August 2020 to $31^{\text {st }}$ March 2021.

Methodology: One hundred and twenty patients of both genders were presented in this study. Patients were aged between 20-70years. Patient's detailed demographics age, sex and mean body mass index were recorded after taking informed written consent. Patients of schizophrenia received electroconvulsive treatment. Frequency of immediate complications was observed after each session of electroconvulsive treatment and at the end of electroconvulsive treatment frequency of long term complications were observed.

Results: Sixty five (54.17\%) were males and 55 (45.83\%) were females with mean age were $40.14 \pm 3.45$ years and mean body mass index $22.14 \pm 6.12 \mathrm{~kg} / \mathrm{m}^{2}$. Mean electroconvulsive treatment sessions was $88.13 \pm 6.87$. Mean hospitalization stay was $3.4 \pm 2.04$ weeks. Frequency of immediate complications were $25(20.83 \%)$ among patients after electroconvulsive treatment session. Among $20.83 \%$, frequency of body aches was 7 (8.83\%), headache was in $11(9.17 \%)$, frequency of transient amnesia was among $3(2.5 \%)$ and hypertension was among $4(3.33 \%)$. Significantly no any delay complications were observed in continuously sessions among enrolled cases.

Conclusion: The use of electroconvulsive treatment sessions in patients of schizophrenia was effective because no any delay complications were observed in this treatment.

Keywords: Schizophrenia, Electroconvulsive treatment (ECT), Treatment sessions
\end{abstract}

\section{INTRODUCTION}

Introduced in 1938 and used for almost 80 years, electroconvulsive therapy, it requires an electrical current in the brain through the head, which causes an asthma seizure $^{1}$ and muscle relaxant. Electroconvulsive treatment is widely used in various severe, therapeutically refractory or treating-resistant psychiatric conditions, including large depressive $^{2}$, schizophrenia, and bipolar disorders, as one of the most important biological therapies. Research has shown that ECT has caused major changes to the physiology and chemistry of the molecular brain, accounting for its therapeutic impact. ${ }^{3}$

A retrospective graphic examination of 19.982 inpatients aged between 18 and 59 years found that ECT was $66.3 \%$ in severe depression, $55.2 \%$ in schizophrenia, $68.4 \%$ in bipolar disorders and $28.6 \%$ in other psychiatric disorders. ${ }^{4}$ China is the most frequent patient with ECT. A longitudinal research conducted in 1,364 years of age and older staff showed that in schizophrenia, the share of ECT was 57.0 percent, in severe depression 53.4 percent, in bipolar disorder 57.8 percent and in other diagnoses $32.4 .^{5}$ Zhang et $\mathrm{al}^{6}$ investigated ECT prevalence in Chinese adolescent psychiatric patients, and concluded that for schizophrenia, the incidence of ECT use was $46.5 \%$, for bipolar, $41.8 \%$ and $23.9 \%$ for other diagnoses.

In adult patients with schizophrenia, electroconvulsive therapy is safe and effective particularly when a quick response is needed. ${ }^{7}$ Some ECT effectiveness trials showed important advantages in the treatment of schizophrenia in children and adolescents. ${ }^{8,9}$ Current neurosciences show that while issues with short-term memory also arise after electroconvulsive therapy, there is a reduced prevalence of long-term problems. However, we do have shortcomings with regard to long-term cognitive issues following ECT like memory. ${ }^{10}$ The key drawback of the wider use of ECT is cognitive effects, especially occasional acute confusion shortly post-treatment, retrograde amnesia and some long-term autobiographic (personal) memory losses. ${ }^{11}$ Some memory elements are either unchanged or enhanced.

Electroconvulsive treatment is practiced markedly differently from more advanced countries in countries with reduced resources; while ECT administration without anesthesia is not ideal, it is often appropriate to apply it in view of severe financial constraints. The ECT administration analysis was carried out on 1520 patients (29\% of total facility admissions, 1352 (88.9\%) of whom had no kind of anesthesia and no adverse reactions had been registered during the procedure. ${ }^{12}$ Using the Clinically Global Impression-Severity (CGI-S) questionnaire the severity of each patient's psychopathology before and after ECT was measured. The aggression levels before and after the therapy were assessed using the Scale-Revised Staff Observation Aggression (SOAS-R) and the operation levels before and after therapy were assessed using a Global Function Assessment (GAF) questionnaire. ${ }^{13}$ The treating doctors also stated the reasons for the selection of 
several therapies for ECT in these patients and their care schemes.

\section{MATERIALS AND METHODS}

This retrospective study was conducted at Department of Psychiatry, Balochistan Institute of Psychiatry \& Behavioural Sciences, Quetta $1^{\text {st }}$ August 2020 to $31^{\text {st }}$ March 2021 and comprised of 120 patients. Baseline details of patient's age, sex and body mass were calculated after taking written consent. Patients who had chronic medical illness (cardiovascular, respiratory disease) and those did not give written consent were excluded from this study. Patients were selected for ECT when they showed no improvement on pharmacotherapy alone. Patients of schizophrenia were aged between 20-70years. Frequency of immediate complications was observed after each session of ECT and at the end of ECT frequency of long term complications were observed. Categorical variables were assessed by frequency and percentage but descriptive variables were calculated by standard deviation. Complete data was analyzed by SPSS 24.

\section{RESULTS}

There were 65 (54.17\%) males and 55 (45.83\%) females with mean age was $40.14 \pm 3.45$ years and mean body mass index $22.14 \pm 6.12 \mathrm{~kg} / \mathrm{m}^{2}$. Mean electroconvulsive treatment sessions was $88.13 \pm 6.87$. Mean hospitalization stay was $3.4 \pm 2.04$ weeks (Table 1). Among 120 patients, most of the patients $66.7 \%$ were from the age group 20-40 years and received higher number of ECT sessions while remaining $33.3 \%$ were $>40$ years and received minimum sessions (Table 2).

Frequency of immediate complications were 25 $(20.83 \%)$ among patients after ECT session. Among $20.83 \%$, frequency of body aches was $7(8.83 \%)$, headache was in $11(9.17 \%)$, frequency of transient amnesia was among $3(2.5 \%)$ and hypertension was among 4 (3.33\%).Significantly no any delay complications were observed in continuously sessions among enrolled cases (Table 3).

Table 1: Demographic details of the patients

\begin{tabular}{|l|l|l|}
\hline Variable & No. & $\%$ \\
\hline Gender & 65 & 54.17 \\
\hline Male & 55 & 45.83 \\
\hline Female & $40.14 \pm 3.45$ \\
\hline Mean age (years) & $22.14 \pm 6.12$ \\
\hline Mean BMI (kg/m²) & $88.13 \pm 6.87$ \\
\hline Mean hospitalization (weeks) & $3.4 \pm 2.04$ & \\
\hline Mean ECT sessions &
\end{tabular}

Table 2: Association of ECT with respect to age $(n=120)$

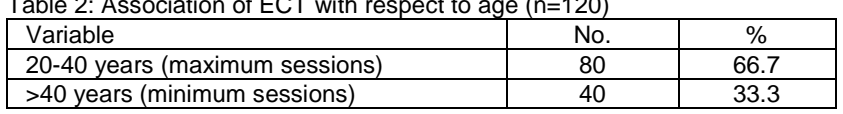

Table 3: Frequency of complications among schizophrenia patients $(n=120)$

\begin{tabular}{|l|c|c|}
\hline Complication & No. & $\%$ \\
\hline No complication & 95 & 79.17 \\
\hline Complication & 25 & 20.83 \\
\hline Body aches & 7 & 8.83 \\
\hline Teadache & 11 & 9.17 \\
\hline Hypertension & 3 & 2.5 \\
\hline
\end{tabular}

\section{DISCUSSION}

Though electroconvulsive treatment is well known and evidence-based in the acute phase of major psychiatric conditions, ECT knowledge is lacking. Sixty five (54.17\%) were males and 55 (45.83\%) were females in this study. Mean age of the patients were $40.14 \pm 3.45$ years with mean BMI 22.14 $\pm 6.12 \mathrm{~kg} / \mathrm{m}^{2}$. Mean ECT sessions was $88.13 \pm 6.87$. Mean hospitalization stay was $3.4 \pm 2.04$ weeks. These findings were comparable to the many previous studies. ${ }^{14,17}$ While Lévy-Rueff et al $^{18}$ reported $M-E C T$ in schizophrenic or schizo-affective patients with a $48 \pm 20$ year mean age. Suzuki et $\mathrm{al}^{17}$ reported M-ECT in a collection of schizophrenia with 61 year medium age patients.

This study only included schizophrenic patients. There were no patients with bipolar affective disorder who received multiple ECT in our hospital. This is either due to the fact that patients who have affective distress typically do not have to have a lot of ECT, the fact that doctors treating them do not provide multiple ECTs, or because of the technical and logistical complexities involved in offering multiple ECT treatments. This research covers a special patient group and the literature contains few reports on these patients. A group of schizophrenia or schizoaffective disorder patients who had been hospitalized an average 10 months before M-ECT were identified by Lévy-Rueff et al ${ }^{18}$ but, on average, hospitalized for two months after initial care. Russell et al $^{19}$ reported having been in the group most of the year before beginning C/M-ECT their series of bipolar affective and schizoaffective patients.

In the current study frequency of immediate complications were $25(20.83 \%)$ among patients after ECT session. Among $20.83 \%$, frequency of body aches was $7(8.83 \%)$, headache was in $11(9.17 \%)$, frequency of transient amnesia was among $3(2.5 \%)$ and hypertension was among 4 (3.33\%). Significatly no any delay complications were observed in continuously sessions among enrolled cases. These were comparable to the previous studies. ${ }^{20-23}$ While ECT under anesthesia is ideal, it is hard to do in any patient even in countries such as Pakistan, where there is a lack of resources. There seems to be no distinction between the two ECT modalities in delayed complications. Furthermore, ECT is often determined for patients with extreme mental conditions that can place suicidal patients, stupor, catatonia or serious self-neglect of their own or others. Therefore ECT will save lives in such a situation. ${ }^{24,25}$

The side-effects and complications observed in other studies ${ }^{17,19}$ are common, but are minor when found, including in elderly and sometimes physically ill patients. Minor side effects, such as headaches, nausea and muscles, are no different from those recorded after acute ECT treatment. Keys, long apnea, heart dysrhythmias, epileptic or delirium status, and other major complications are very uncommon. Both of these need an expert team to closely track each ECT treatment and any one after it.

Electroconvulsive treatment can cause some adverse effects, including memory impairment and new learning, long-term seizures, general anesthesia risk and other minor effects. Some reports, however, do not agree with this view. De Serna et al. found no substantial improvement discrepancies between the ECT community and the nonECT group over a two-year follow-up in clinical or 
neuropsychological variables over time. There is also no detrimental effect of ECT in their study on long-term neuropsychological variables. ${ }^{26}$ The report of Lima et $\mathrm{al}^{27}$ found that ECT is highly effective for treating multiple adolescent psychological conditions with low and relatively mild effects in a systematic review of 39 trials.

\section{CONCLUSION}

The use of electroconvulsive treatment sessions in patients with schizophrenia was effective because no any delay complications were observed in this treatment.

\section{REFERENCES}

1. Saleem R, Rauf S, Jehangir S. Efficacy of electroconvulsive therapy in treatment resistant depression. Pak Armed Forces Med J 2018; 68 (4): 969-74.

2. Leiknes KA, Jarosh-von Schweder L, Hoie B. Contemporary use and practice of electroconvulsive therapy worldwide. Brain Behav 2012;2(3):283-344.

3. Singh A, Kar SK. How electroconvulsive therapy works?: understanding the neurobiological mechanisms. Clin Psychopharmacol Neuro Sci 2017; 15(3): 210-21.

4. Wang ZM, Zhu H, Pan YL, Chiu HF, Correll CU, Ungvari GS, et al. Electroconvulsive therapy and its association with demographic and clinical characteristics in Chinese psychiatric patients. J ECT 2015;31(2):114-8.

5. An FR, Zhang L, Zhang QE, Ungvari GS, Ng CH, Chiu HFK, et al. Electroconvulsive therapy and its relationships with clinical characteristics and quality of life in Chinese psychiatric patients. Psychiatry Res 2016;246:246-9.

6. Zhang QE, Wang ZM, Sha S, Ng CH, Seiner SJ, Welch CA, et al. Common use of electroconvulsive therapy for Chinese adolescent psychiatric patients. J ECT 2016;32(4):251-5.

7. Tharyan $\mathrm{P}$, Adams CE. Electroconvulsive therapy for schizophrenia. Cochrane Database Syst Rev 2005;18:CD000076.

8. Baeza I, Flamarique I, Garrido JM, et al. Clinical experience using electroconvulsive therapy in adolescents with schizophrenia spectrum disorders. J Child Adolesc Psychopharmacol 2010; 20:205-9.

9. Maoz H, Nitzan U, Goldwyn Y, Krieger I, Bloch Y. When can we predict the outcome of an electroconvulsive therapy course in adolescents? A retrospective study. J ECT 2018;34:104-7.

10. Coetzer R. Depression, memory and electroconvulsive therapy. BJ Psych Bull 2019; 43(2): 51-53.

11. Semkovska M, McLoughlin DM. Objective cognitive performance associated with electroconvulsive therapy for depression: a systematic review and meta-analysis. Biol Psychiatry 2010; 68(6): 568-77.

12. Minhas MH, Ostroff R. Practice of electroconvulsive therapy in a tertiary care hospital in Pakistan J ECT 2012;28(1):7-9.
13. Nijman $\mathrm{H}$, Palmstierna T. Measuring aggression with the staff observation aggression scale-revised. Acta Psychiatr Scand Suppl 2002;412:101-2.

14. Iancu I, Pick N, Seener-Lorsh O, Dannon P. Patients with schizophrenia or schizoaffective disorder who receive multiple electroconvulsive therapy sessions: characteristics, indications, and results. Neuropsychiatr Dis Treat 2015;11:853-62.

15. Wang S, Yang C, Jia J, et al. Use of electroconvulsive therapy in adolescents with schizophrenia in China. Child Adolesc Psychiatry Ment Health 2018;12:49.

16. O'Connor DW, Gardner B, Presnell I, Singh D, Tsanglis M, White $\mathrm{E}$. The effectiveness of continuation-maintenance ECT in reducing depressed older patients' hospital readmissions. J Affect Disord 2010;120:62-66.

17. Suzuki K, Takano T, Ebina Y, Takamatsu K, Awata S, Matsuoka $\mathrm{H}$. Continuation electroconvulsive therapy to prevent relapse of schizophrenia in relapse-prone patients. $\mathrm{J}$ ECT 2007;23:204-5.

18. Lévy-Rueff M, Gourevitch R, Loo H, Olié JP, Amado I. Maintenance electroconvulsive therapy: an alternative treatment for refractory schizophrenia and schizoaffective disorders. Psychiatry Res 2010;175:280-83.

19. Russell JC, Rasmussen KG, O'Connor M, Copeman CA, Ryan DA, Rummans TA. Long-term maintenance ECT: a retrospective review of efficacy and cognitive outcome. $J$ ECT 2003;19:4-9.

20. The UK ECT Review Group. Efficacy and safety of electroconvulsive therapy in depressive disorders: a systematic review and meta-analysis. Lancet 2003;361(9360):799-808.

21. Coetzer R. Depression, memory and electroconvulsive therapy. BJ Psych Bull 2019; 43(2): 51-3.

22. Semkovska M, McLoughlin DM. Objective cognitive performance associated with electroconvulsive therapy for depression: a systematic review and meta-analysis. Biol Psychiatry 2010; 68(6): 568-77.

23. Brown SK, Nowlin RB, Sartorelli R., Smith J, Johnson K. Patient experience of electroconvulsive therapy: a retrospective review of clinical outcomes and satisfaction. $J$ ECT 2018.

24. Waite J, Easton A. ECT Handbook. $3^{\text {rd }}$ ed. London: The Royal College of Psychiatrists 2013.

25. Pagnin DV, de Queiroz SP, Cassano GB. Efficacy of ECT in depression: a meta-analytic review. J ECT 2004; 20(1): 1320.

26. De la Serna E, Flamarique I, Castro-Fornieles J, Pons A, Puig $\mathrm{O}$, Andrés-Perpiña $\mathrm{S}$, et al. Two-year follow-up of cognitive functions in schizophrenia spectrum disorders of adolescent patients treated with electroconvulsive therapy. J Child Adolesc Psychopharmacol 2011;21(6):611-9.

27. Lima NN, Nascimento VB, Peixoto JA, et al. Electroconvulsive therapy use in adolescents: a systematic review. Ann Gen Psychiatry 2013;12:17. 